\title{
The distribution and variability of chlorophyll-a bloom in the southeastern tropical Indian Ocean using Empirical Orthogonal Function analysis
}

\author{
ISKHAQ ISKANDAR ${ }^{1, \vartheta}$, QURNIA WULAN SARI ${ }^{2}$, DEDI SETIABUDIDAYA ${ }^{1}$, INDRA YUSTIAN $^{3}$, BRUCE MONGER $^{4}$ \\ ${ }^{1}$ Department of Physics, Faculty of Mathematics and Natural Sciences, Universitas Sriwijaya. Jl. Palembang - Prabumulih, Km. 32, Inderalaya, OI, \\ Sumatra Selatan, 30662, Indonesia. Tel./Fax.+62-711-580056, ”email: iskhaq@mipa.unsri.ac.id; iskhaq.iskandar@gmail.com \\ ${ }^{2}$ Graduate School of Environmental Science, Universitas Sriwijaya. J1. Padang Selasa, Bukit Besar, Palembang, 30139, Indonesia. \\ ${ }^{3}$ Department of Biology, Faculty of Mathematics and Natural Sciences, Universitas Sriwijaya. Jl. Palembang - Prabumulih, Km. 32, Inderalaya, Ogan \\ Komering 30662, Sumatra Selatan, Indonesia \\ ${ }^{4}$ Department of Earth and Atmospheric Sciences, Cornell University, Ithaca, NY 14853, USA
}

Manuscript received: 20 July 2017. Revision accepted: 4 October 2017.

\begin{abstract}
Iskandar I, Sari QW, Setiabudidaya D, Yustian I, Monger B. 2017. The distribution and variability of chlorophyll-a bloom in the southeastern tropical Indian Ocean using Empirical Orthogonal Function analysis. Biodiversitas 18: 1546-1555. The Indian Ocean Dipole (IOD) events cause anomalously strong upwelling along the sourthen coast of Sumatra-Java leading to the bloom of chlorophyll$a$. An empirical orthogonal function (EOF) analysis was applied to the time series of the satellite-observed chlorophyll- $a$, sea surface temperature (SST) and surface winds. Spatial eigen functions of the first EOF mode revealed the broad areas of coherent temporal variation in chlorophyll- $a$, SST and Ekman pumping, which was observed in the southeastern tropical Indian Ocean (SETIO) region. The corresponding time series of principal component of the first EOF mode revealed a robust seasonal variation and relativley weak inter-annual variation. The second EOF mode exhibited a distinct inter-annual variation with the high surface chlorophyll- $a$ concentration was observed along the southern coast of Sumatra-Java. This high chlorophyll- $a$ concentration is co-located with the low SST, the positive Ekman pumping, and the positive wind-induced mixing. An EOF analysis applied on the seasonal time series showed interesting patterns. The leading EOF mode during the peak IOD season from September to November (SON) showed the high concentration of chlorophyll- $a$ was restricted to the southern coast of Java and was co-located with low SST region. The corresponding time series of principal component of the leading EOF mode showed a significant correlation with the Dipole Mode Index (DMI), however it had no correlation with the Ekman pumping. It could be concluded that the chlorophyll- $a$ bloom during the peak phase of the IOD event was generated by the alongshore upwelling-favorable winds in the preceding season.
\end{abstract}

Keywords: Coastal upwelling, EOF analysis, Indian Ocean Dipole, sea surface chlorophyll- $a$, southeastern tropical Indian Ocean

\section{INTRODUCTION}

The eastern boundary coastal upwelling system in the Indian Ocean has become the main research worldwide due to its strong coupled atmosphere-ocean dynamics, especially its biogeochemical cycling (McCreary et al. 2013; Wiggert et al. 2013). This has an implication on the marine productivity in the eastern boundary upwelling region, which significantly increases due to the upward motion of nutrient-rich water from deep layer to the upper layer. Previous studies have shown that the eastern boundary coastal upwelling systems in the Atlantic and Pacific Oceans are one of the most productive marine environments in the world, which account for about $5 \%$ of the global marine productivity (Pauly and Christensen 1995; Carr 2002).

Unlike the eastern boundaries of the Pacific and Atlantic Oceans, however, the eastern boundary of the Indian Ocean undergoes dramatic seasonal changes (Wyrtki 1961; Qu et al. 2005). The Asian-australian monsoon winds cause the variability of SST and surface circulation in the eastern boundary of the Indian Ocean, particularly the SETIO (Susanto et al. 2001; Sprintall et al.
1999). In addition, the SETIO region is located at crossroads of water masses from the Pacific Ocean that are modified through the Indonesian Throughflow (ITF), the Indonesian Seas, and the equatorial Indian Ocean (Figure 1) (Feng and Wijffels 2002; Wijffels and Meyers 2004; Qu and Meyers 2005; Iskandar et al. 2006, Yu and Potemra 2006). Therefore, the SETIO represents a complex region, displaying biophysical variability from seasonal to interannual time scale.

Within the seasonal time scale, the reversal of monsoon winds plays a dominant role in generating seasonal modulation of the SST in the SETIO region as well as seasonal reversal of the South Java Coastal Currents (Quadfasel and Cresswell 1992; Susanto et al. 2001). During the southeast monsoon from June to September, south-east winds prevail over the SETIO region, generating upwelling along the southern coast of the Lesser Sunda Islands leading to cool condition of SST. On the other hand, the north-west winds are observed over the SETIO region during the northwest monsoon season from December to March. These north-west winds cause onshore Ekman transport and subsequent downward vertical motion along the coast and warm condition of SST. 
The SETIO region is also known as a center for the development of an eastern pole of the Indian Ocean Dipole (IOD) phenomenon (Saji et al. 1999; Webster et al. 1999; Murtugudde et al. 2000). During the positive IOD events, local upwelling along the southern coast of Sumatra-Java raises due to strengthening of south-east winds along the coast. As a consequent, the concentration of chlorophyll- $a$ in this region also increases significantly leading to chlorophyll- $a$ bloom (Susanto and Mara 2005; Iskandar et al. 2009). On the other hand, during the negative IOD events, north-west winds along the coast of Sumatra and Java is very strong leading to a strong down welling and low surface chlorophyll concentration (Susanto and Mara 2005; Horii et al. 2013).

In this study, we investigated the seasonal phaselocking and inter-annual occurrence of chlorophyll- $a$ bloom in the SETIO region. In particular, using a statistical analysis, we examined the main mode of spatial-temporal variability in the concentration of chlorophyll- $a$ in the SETIO region and evaluated its relationship with physical forcing patterns.

\section{MATERIALS AND METHODS}

\section{Study area}

The study area was located in the SETIO region covering an area of $90^{\circ}-150^{\circ} \mathrm{E}$ and $16^{\circ} \mathrm{S}-4^{\circ} \mathrm{N}$ (Figure 1). The SETIO region is a place where the water masses from the Pacific Ocean, South China Sea, Indonesian Seas, and Indian Ocean are meet.

\section{Datasets}

Chlorophyll- $a$ concentration for the SETIO region was obtained from sublicenses of monthly global mapped imagery derived from the Moderate Resolution Imaging Spectroradiometer (MODIS) aboard the Aqua spacecraft. The data were provided by the NASA Goddard Distributed Active Archive Center for a period from July 2002 to
February 2014 at $9 \mathrm{~km}$ horizontal resolution. The surface wind data were obtained from the ERA-Interim of the European Center for Medium Range Weather Forecasts (ECMWF). The monthly gridded data at $0.75^{\circ} \times 0.75^{\circ}$ resolutions from January 2002 to December 2013 were used in this study. As a proxy for upwelling, the vertical transport was computed using the formula $(\mathbf{1} / \boldsymbol{\rho}) \boldsymbol{\nabla} \times \vec{\tau}$, where $\rho$ is the density of seawater and $\overrightarrow{\boldsymbol{\tau}}$ is wind stress. This parameter is then called as the Ekman pumping. Note that, the wind stress was calculated using monthly surface wind data using a constant drag coefficient $\left(1.43 \times 10^{-3}\right)$ and air density $\left(1.225 \mathrm{~kg} \mathrm{~m}^{-3}\right)$ following Weisberg and Wang (1997).

Monthly SST imagery was obtained from the National Oceanic and Atmospheric Administration (NOAA) Optimum Interpolation (OI) (Reynold et al. 2007). This SST product combined the Advanced Very HighResolution Radiometer (AVHRR) satellite data and direct measurements from ships and buoys collected under the International Comprehensive Ocean-atmosphere Data Set (INCOAD) (Worley et al. 2005). The dataset from January 2002 to December 2013 on $0.25^{\circ} \times 0.25^{\circ}$ grids was used in this study.

\section{Data analysis}

EOF technique was used to examine the spatial and temporal variations of all parameters (chlorophyll- $a$, ocean wind speed, and SST). EOF analysis extracts multivariate datasets into a series of orthogonal functions or modes based on the covariance matrix of the data (Emery and Thomson 2004). Every mode consists of the spatial eigen functions, representing the spatial patterns of variability in each time, and the principal components where a time series showed on how the spatial patterns was varied with time. Each subsequent mode was being orthogonal, which is consistently the same as the previous one. Typically, the leading mode explains the highest amount of the total variance in which the variations of its spatial and temporal patterns are strongly coupled.

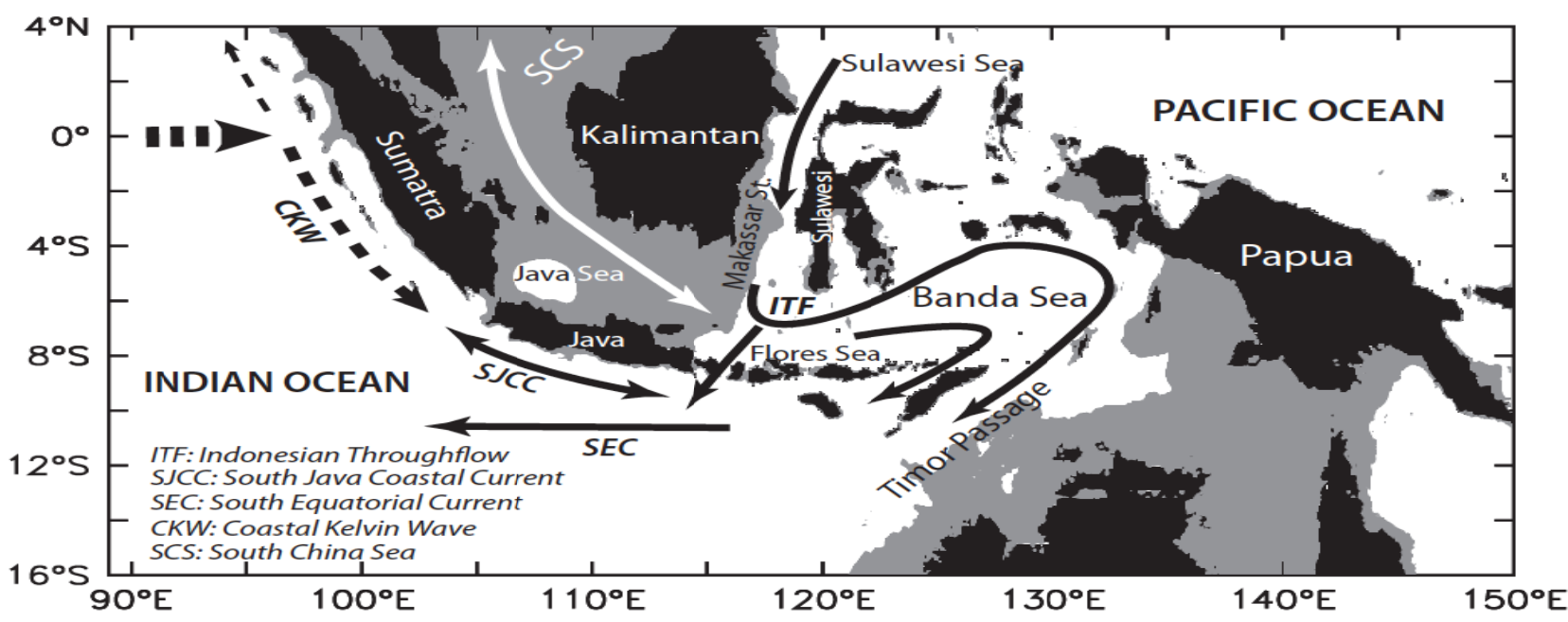

Figure 1. Map of the southeastern tropical Indian Ocean 
To reduce the amount of missing chlorophyll values due to the cloud cover and to generally remove high spatial frequency noise due to the inherent limitation of measurement capabilities of the satellite instrument, an area-weighted re-gridding into $0.4^{\circ} \times 0.4^{\circ}$ spatial resolutions was applied to the chlorophyll- $a$ data. The average of seasonal composite was then applied to the $0.4^{\circ}$ $\times 0.4^{\circ}$ chlorophyll- $a$ data to reduce missing values and high-frequency noise, The result was a set of 3-month composite- $a$ verage of chlorophyll- $a$ image (e.g. DJF, MAM, JJA, and SON) spanning from 2002 to 2013. Chlorophyll- $a$ data at shallow water locations, for a depth less than $100 \mathrm{~m}$, were then removed. Finally, temporal anomalies were calculated by subtracting the long-term mean at each grid point. A similar procedure was applied to the SST and surface wind data, with an exception that the data do not contain any missing values.

\section{RESULTS AND DISCUSSION}

\section{Spatial characteristics}

Figure 2 shows the spatial patterns of the temporal standard deviation for chlorophyll- $a$, SST, Ekman pumping and a proxy index for the wind mixing $\left(U^{3}\right) . U^{3}$ represents the wind-induced surface ocean mixing that is proportional to the cube of the wind fields (Ueyama and Monger 2005).
The standard deviation for chlorophyll- $a$ showed that the area of high variability was confined along the southern coast of Indonesia, extending from the Nusa Tenggara Islands in the east to the southern coast of Sumatra in the west (Figure 2.A). This suggests that the presence of strong coastal upwelling was forced by the alongshore wind stress. In addition, the map also exhibited the relative-high variability of chlorophyll- $a$ concentration in the eastern Banda Sea. Similar features were also observed for the SST, though with an offshore extension (Figure 2.B). This SST feature was not surprising; because a previous study has shown that high SST variations associated with the upwelling off Java progressed westward from the southern coast of the Nusa Tenggara Islands to the southern coast of Sumatra (Susanto et al. 2001). The Ekman pumping also showed the high variability along the southern coast of Java and Sumatra suggesting the presence of coastal upwelling (Figure 2.C). High variability in the Ekman pumping was also found in the eastern Banda Sea, which showed the high variability of the chlorophyll- $a$ concentration. Wind-induced mixing showed two areas with high variability (Figure 2.D). The first area was in the offshore west of about $105^{\circ} \mathrm{E}$ and the second area was in the Timor Sea. The former one corresponded to the location of high SST and strong winds during the negative IOD event.
A. Standard deviation of Chl-a (log: $\left.\mathrm{mg} / \mathrm{m}^{3}\right)$

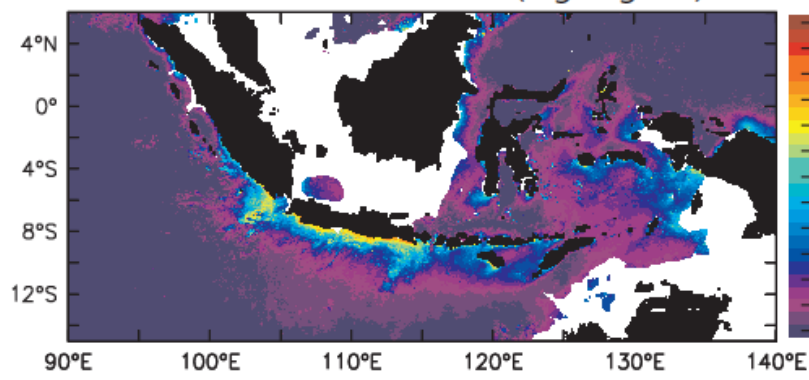

C. Standard deviation of SST $\left({ }^{\circ} \mathrm{C}\right)$

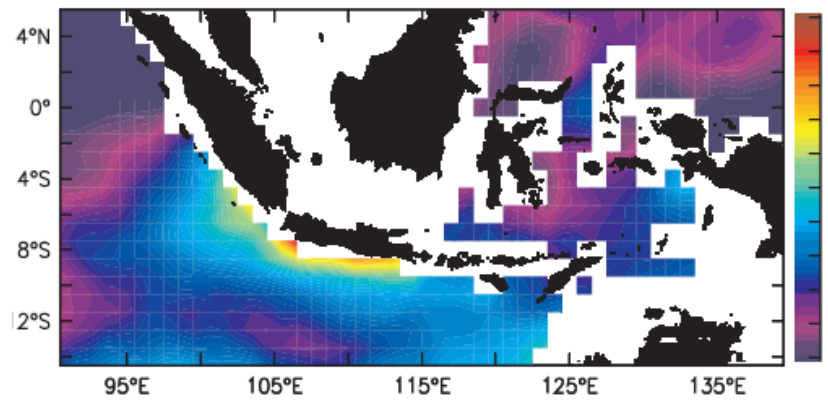

B. 5tandard deviation of Ekman pumping ( $\left.\times 10^{-2} \mathrm{~N} / \mathrm{m}^{3} \mathrm{~s}\right)$

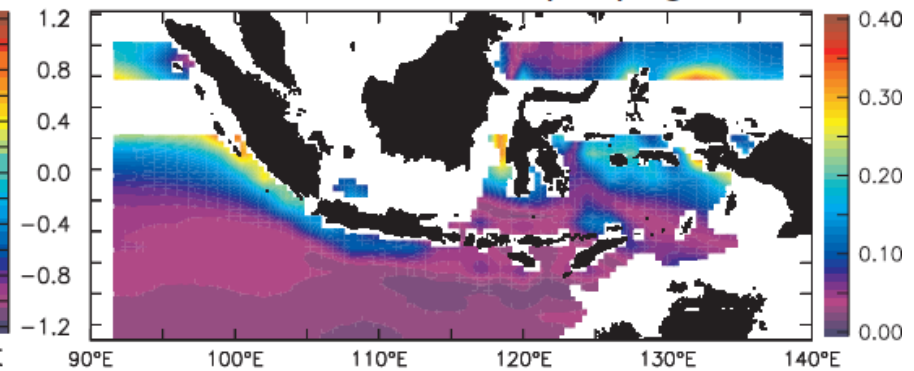

D. Standard deviation of wind mixing $(\mathrm{m} / \mathrm{s})^{3}$

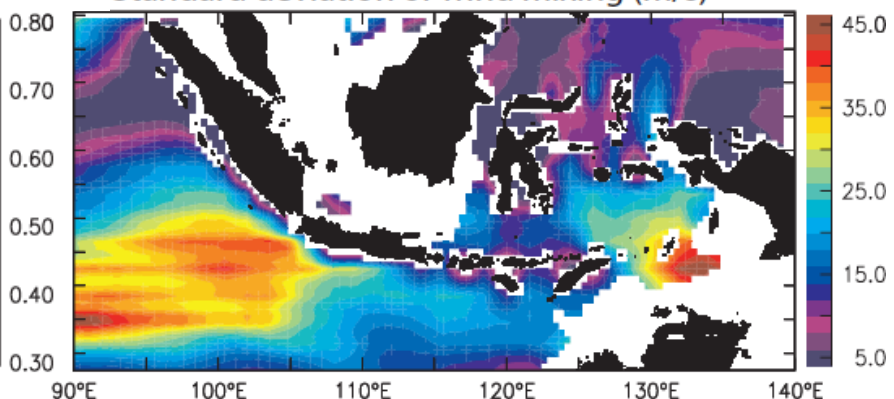

Figure 2. Standard deviations of (A) chlorophyll- $a$ from the Moderate Resolution Imaging Spectroradiometer (MODIS) aboard the Aqua spacecraft from July 2002 to February 2014 (B) SST of the Advanced Very High-Resolution Radiometer (AVHRR) satellite data from January 2002 to December 2013, (C) Ekman pumping, and (D) wind-induced mixing $\left(u^{3}\right)$ derived from the ERA-Interim of the European Center for Medium Range Weather Forecasts (ECMWF) from January 2002 to December 2013. The vertical axes indicate the latitude, while the horizontal axes represent the longitude 


\section{Seasonal variations}

The spatial functions of the leading EOF mode for monthly chlorophyll-a concentration, SST, Ekman pumping and wind-induced mixing is presented in Figure 3. The explanation of variances for the first two EOF modes is summarized in Table 1. The chlorophyll- $a$ pattern of the first EOF mode, which accounts for $47.8 \%$ of the total variance, revealed the presence of the high-relative variability along the southern coasts of Java and Nusa Tenggara Island as well as in the eastern Banda Sea (Figure $3 a)$. The pattern also revealed a distinct offshore extension of high variability of chlorophyll- $a$ concentration.

The variability of spatial pattern of SST in each month from the first EOF mode obtained $72.8 \%$ of the total variance (Figure 3.B). The pattern showed that the temporal SST variability was relatively strong and broadly covering the SETIO region and the Banda Sea. It means that $180^{\circ}$ out of phase with the chlorophyll- $a$ variability for these same regions (Figure 3.A). Based on the data of leading EOF mode of the Ekman pumping, it showed that the variability of Ekman pumping covered up to $83.0 \%$ of the total variance. Most of them depicted the relatively strong temporal variability especially in the restricted region i.e the southern coast Sumatra and Java. This strong variability also occured in the northern side of the Banda Sea, which was in the roughly phase of chlorophyll- $a$ variability (Figure 3.C). Although the stronger phase of variability occurred near the south Sumatra coast; however, the variability based on Ekman pumping data was relatively weak. The same condition was also observed in the south of Nusa Tenggara Islands. This indicated that the presence of coastal upwelling caused two-contrast condition i.e the high concentration of chlorophyll- $a$ and the low data of SST in this region. The variability of wind- induced mixing based on the first EOF mode analysis accounted for $57.7 \%$ of the total variance (Figure 3.D). The most striking spatial pattern wit a strong variability was located in Sumatra-Java, which was also the area of the highest wind-induced mixing variability as shown in Figure 2.D.

The time series of the principal component analyzed from the leading EOF mode for chlorophyll- $a$, SST, Ekman pumping and wind-induced mixing is presented in Figure 4. It was not surprising that the most apparent feature of all time series was a seasonal cycle, which was associated with the seasonal change in the monsoon winds. The EOF time series of chlorophyll- $a$ was highly correlated to those of SST, Ekman pumping, and wind-induced mixing with coefficient correlation exceeding 0.9 (Table 1). In addition to seasonal feature, the time series of the leading EOF modes also indicated inter-annual signal. For example, the chlorophyll- $a$ time series showed the relatively high weight between 2006 and 2008, which were defined as the IOD years (Iskandar et al. 2013). Similar signals were also observed in other time series indicating the SETIO region also experienced inter-annual variation. Statistical analysis showed that all time series were significantly correlated to the Dipole Mode Index (DMI) time series (Table 2).

Table 1. Percentage of variance of the first-two EOF modes from each spatial and temporal variations parameters

\begin{tabular}{lll}
\hline Variables & EOF-1 & EOF-2 \\
\hline Chlorophyll- $a$ & $47.8 \%$ & $9.1 \%$ \\
SST & $72.8 \%$ & $15.1 \%$ \\
Ekman pumping & $83.0 \%$ & $6.2 \%$ \\
Wind-induced mixing & $57.7 \%$ & $15.4 \%$ \\
\hline
\end{tabular}

A. EOF-1 Chla $(47.8 \%)$

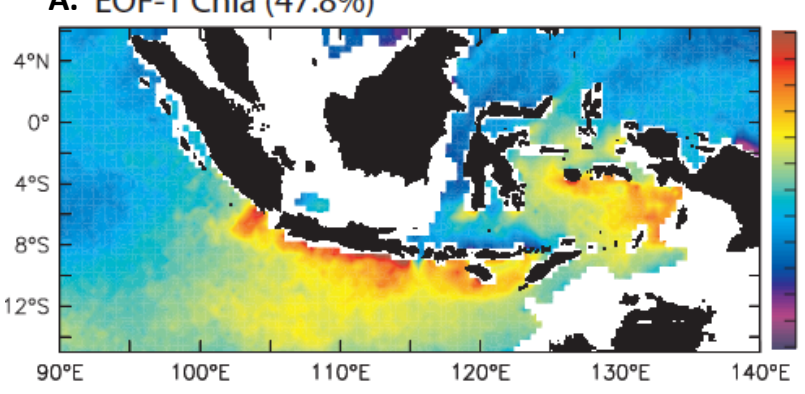

C. EOF-1 SST $(72.8 \%)$

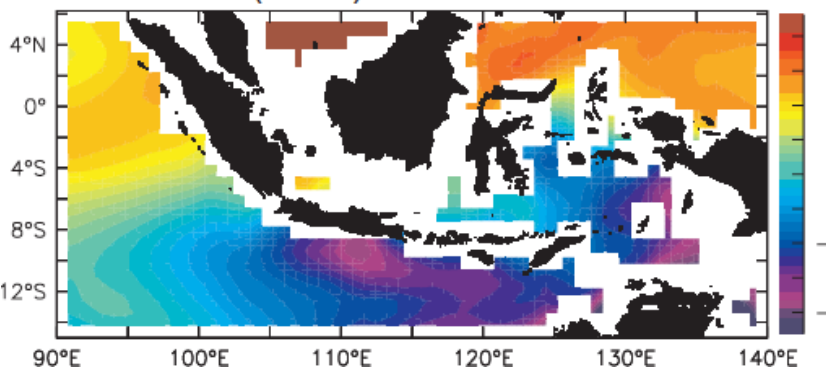

B. EOF-1 Wind curl (83.0\%)

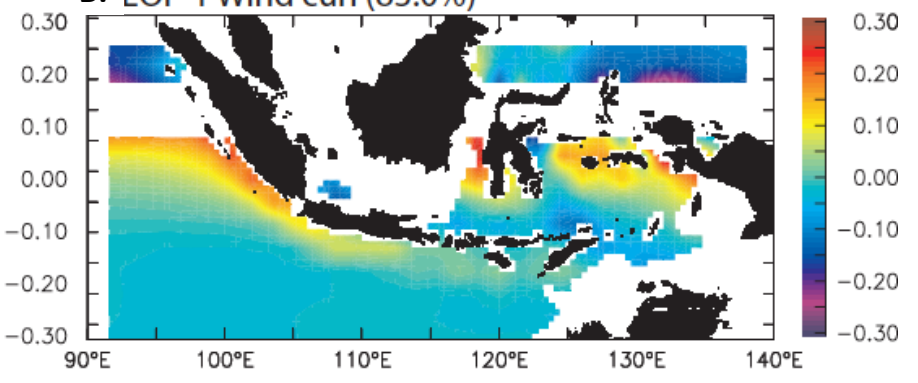

D. EOF-1 wind mixing (57.7\%)

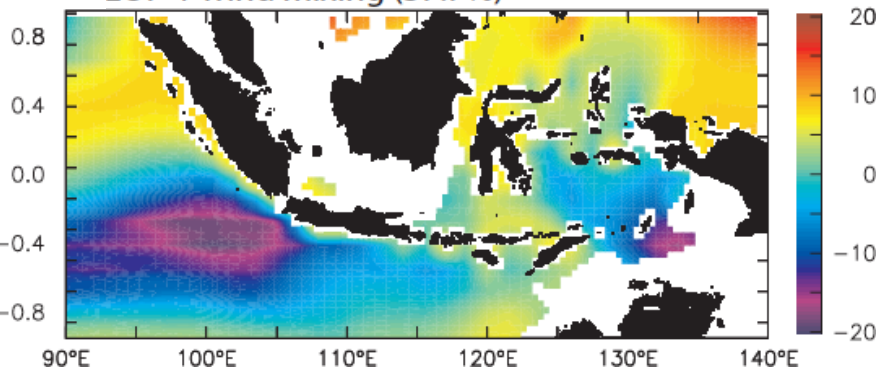

Figure 3. Spatial pattern of eigen functions observed from the first EOF mode (A) chlorophyll- $a$, (B) SST, (C) Ekman pumping, and (D) wind-induced mixing 
Table 2. Correlation coefficients between the IOD and first two EOF modes of chlorophyll- $a$, SST, Ekman pumping, and windinduced mixing.

\begin{tabular}{lcccc}
\hline & \multicolumn{2}{c}{ IOD } & \multicolumn{2}{c}{ Chlorophyll } \\
\cline { 2 - 5 } & EOF-1 & EOF-2 & EOF-1 & EOF-2 \\
\hline Chlorophyll & $0.41^{*}$ & $0.54^{*}$ & - & - \\
SST & $-0.38^{*}$ & -0.20 & $-0.92^{*}$ & $-0.82^{*}$ \\
Ekman pumping & $0.36^{*}$ & $0.41^{*}$ & $0.94^{*}$ & $0.75^{*}$ \\
Wind-induced mixing & $-0.33^{*}$ & -0.20 & $-0.92^{*}$ & -0.02 \\
\hline
\end{tabular}

Note: * Significant at $90 \%$ confidence level

The spatial patterns of the second EOF mode of the chlorophyll- $a$, SST, Ekman pumping, and wind-induced mixing is presented in Figure 5. In contrast to the first EOF mode spatial pattern, the second mode pattern of chlorophyll- $a$ accounting for $9.1 \%$ of the total variance. It revealed that the variability of chlorophyll- $a$ in the western part of the study area was different with the eastern part of the study area (Figure 5.A). The second EOF mode of the SST showed $15.1 \%$ of the total variance and also showed an east-west asymmetry, but the variability is $180^{\circ}$ out of phase with the second mode variability for chlorophyll- $a$ (Figure 5.B). The variability of Ekman pumping analyzed from second EOF mode had $6.2 \%$ of the total variance (Figure 5.C). Its spatial pattern showed the positive weights in Sumatra, but it had, negative weights in the south Java and Nusa Tenggara as well as in the Banda Sea. This indicated that the variability in Sumatra was significantly difference with the other regions. The positive weights of the Ekman pumping were in line with the positive weights of chlorophyll- $a$ and negative weights of the SST. On the other hand, the negative weights of the Ekman pumping appeared in the area of negative weights of chlorophyll- $a$ and positive weights of the SST (Figs. 5.A-C). Spatial pattern of the second EOF mode of the wind-induced mixing, which accounts for $15.4 \%$ of the total variance, revealed that there were two distinct areas in the SETIO region (Figure 5.D). The first area, located southwest of $\left(10^{\circ} \mathrm{S}, 100^{\circ} \mathrm{E}\right)$, was characterized by prominent negative weights. The second area was characterized by positive weights located near the coast extending westward from the south of Nusa Tenggara Islands to the west of Sumatra with maximum weights near the coast of Sumatra. The strongest positive weights for wind-induced mixing were located in the positive weights of chlorophyll- $a$ and negative weights of SST. This observation was consistent with the limit nutrient in the regions, which happened due to the impact of wind-induced mixing bringing nutrient-rich and also the effect of low SST water moving from subsurface to the mixed layer resulting in the promotion of positive distribution of chlorophyll- $a$ and negative SST.

The time series of the principal component for the second EOF mode is presented in Figure 6. Apparently, interannual variation dominated the variability of the time series with two distinct signals in 2006 and 2010, which correspond to the positive and negative IOD events, respectively (Horii et al. 2013). The principal time series of chlorophyll- $a$ and Ekman pumping was highly correlated to the DMI time series with coefficient correlation of 0.54 and 0.41 , respectively. However, the principal time series of the SST and wind-induced mixing exhibit low correlation with the DMI, where the coefficient correlation for both time series is 0.2 and only significant at $80 \%$ confidence level.
A. PCEOF-1 Chla and DMI ( $r=0.41)$
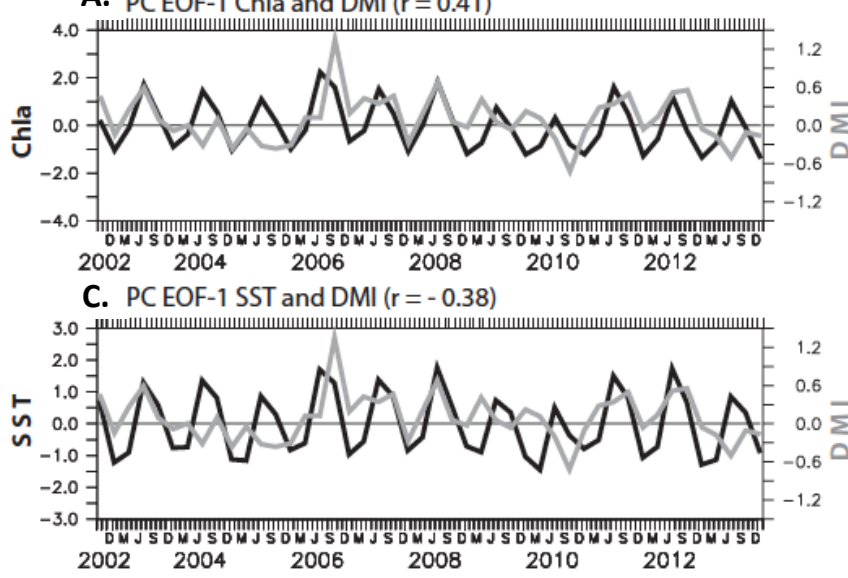

B. PCEOF-1 Ekman pumping and DMI $(r=0.36)$

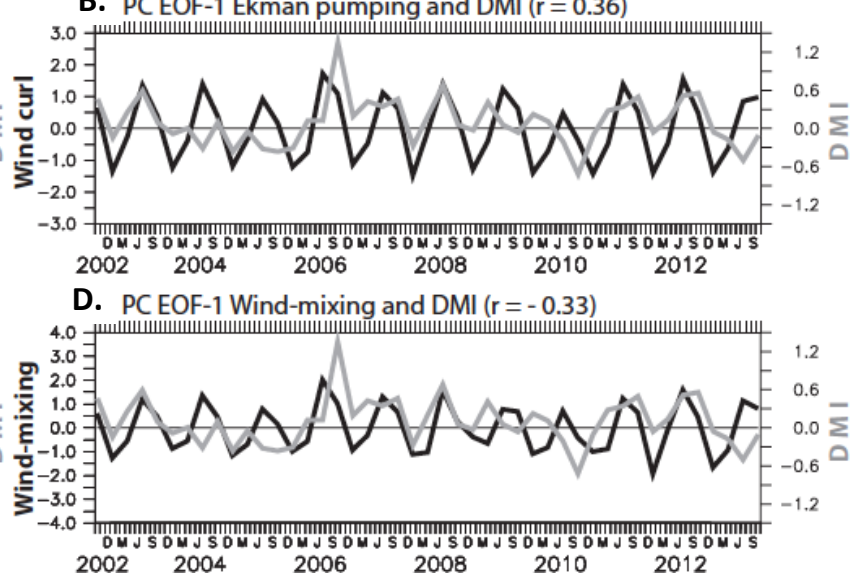

Figure 4. Principal components (black) for the first EOF mode of (A) chlorophyll- $a$, (B) SST, (C) Ekman pumping, and (D) windinduced mixing. Time series of the DMI (gray) was shown in each panel. The DMI was calculated as a gradient of sea surface temperature anomaly averaged over the western $\left(10^{\circ} \mathrm{S}-10^{\circ} \mathrm{N}, 50^{\circ} \mathrm{E}-70^{\circ} \mathrm{E}\right)$ and the eastern $\left(10^{\circ} \mathrm{S}-\mathrm{Equator}, 90^{\circ} \mathrm{E}-110^{\circ} \mathrm{E}\right)$ regions $(\mathrm{Saji}$ et al. 1999). The time series of SST and wind-induced mixing were flipped. 
A. EOF-2 Chla (9.1\%)

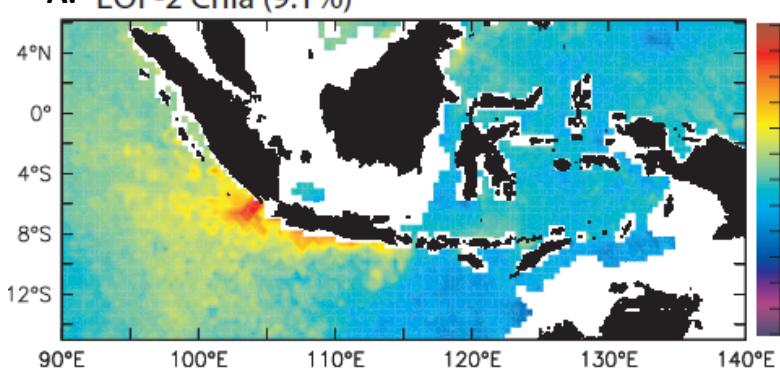

C. EOF-2 SST (15.1\%)

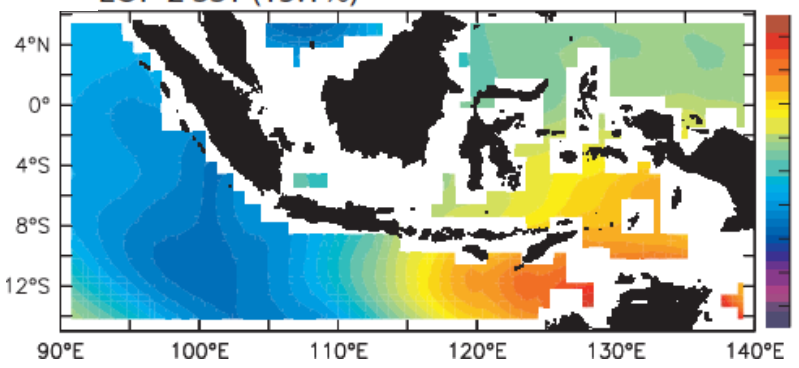

Figure 5. Same as in Figure 3 except for the second EOF mode

\section{Interannual variations}

In order to evaluate the inter-annual variation of chlorophyll- $a$ blooms in the Sumatra and Java associated with the occurrence of the IOD events, we performed an EOF analysis on the seasonal averages. Here, the EOF analysis was applied to the individual season, specifically from June to August (JJA) and separately from the September to November (SON) seasons. Previous study has shown that the IOD event was developed in summer (JJA), which was correlated with the upwelling season in the SETIO region, and reaches its peak in boreal fall (SON) (Saji et al. 1999).

Figure 7 presents the spatial pattern of the first EOF mode for JJA season. Variance of the first EOF for each
B. EOF-2 Ekman pumping (6.2\%)

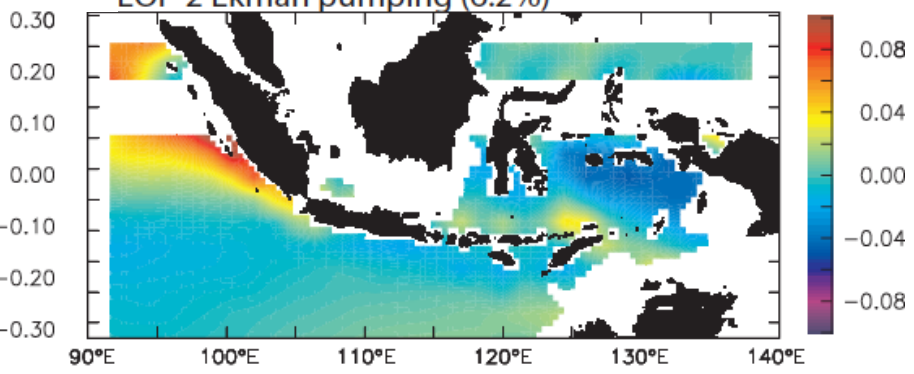

D. EOF-2 Wind-mixing (15.4\%)
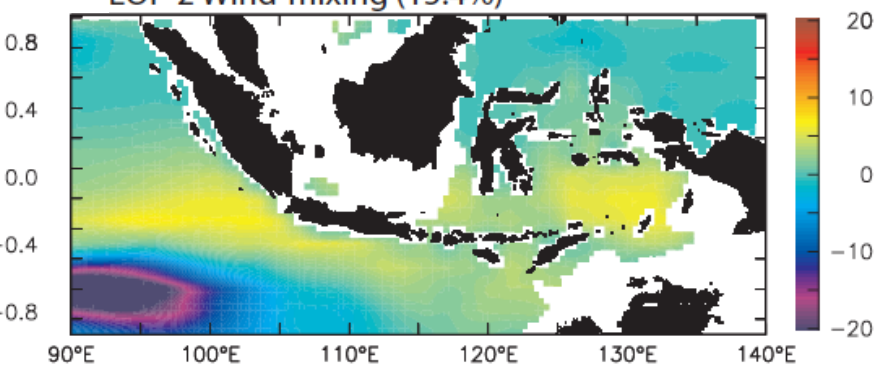

variable was summarized in Table 3. It was shown that the first EOF mode of all variables explained most of the total variance and their spatial patterns resemble those of the first EOF mode for the full season (see Figure 3). The first EOF mode of the chlorophyll- $a$ covered $98.2 \%$ of the total variance. Its spatial pattern was characterized by strongly positive weights along the southern coast of Java and Nusa Tenggara Islands as well as in the southern tip of Sumatra (Figure 7.A). Strong positive weights were also found in the Banda Sea, which was mostly concentrated in the eastern Banda Sea. In addition, there was an offshore extension of positive weights in south Java, although it was relatively weaker compared to that of the first EOF mode for the full season.
A. PC EOF-2 Chla and DMI ( $r=0.54)$

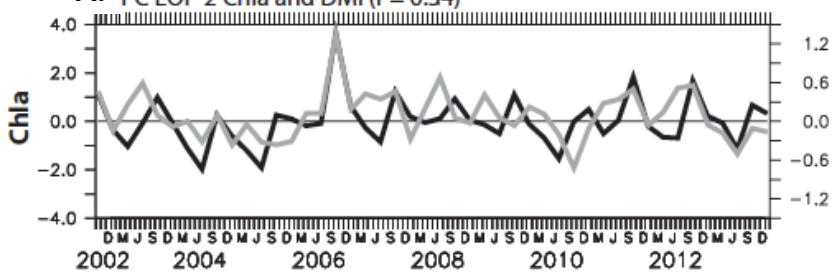

C. PC EOF-2 SST and DMI ( $r=-0.2)$

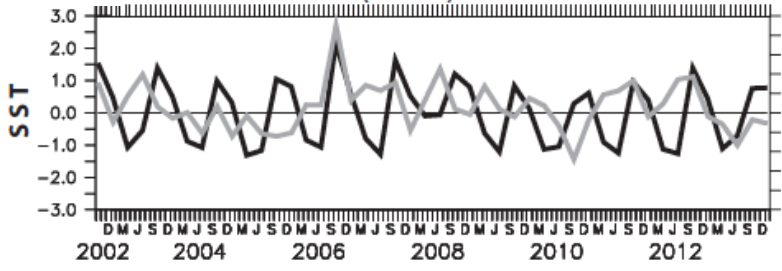

B. PCEOF-2 Ekman pumping and DMI $(r=0.41)$

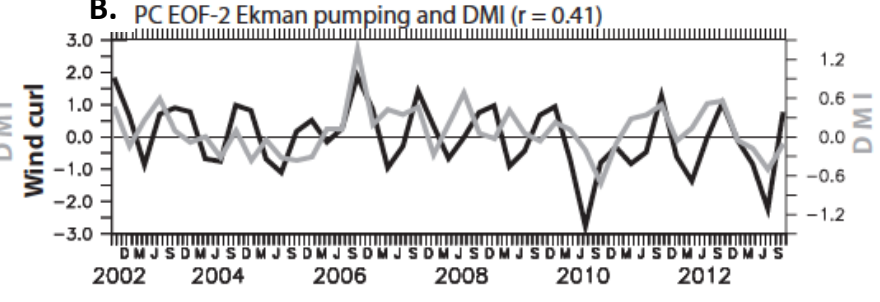

D. PC EOF-2 Wind-mixing and DMI $(r=-0.2)$

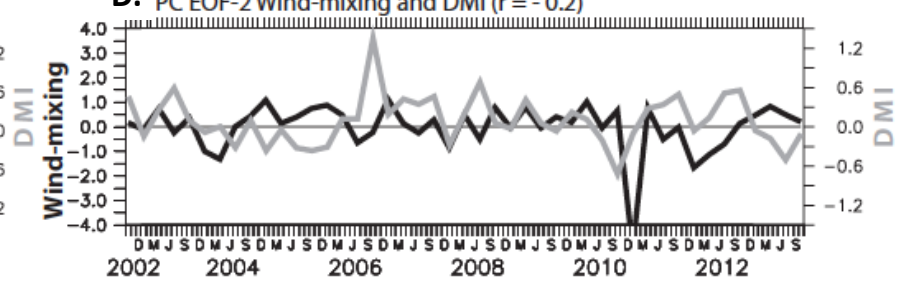

Figure 6. Same as in Figure 4 except for the second EOF mode 
A. EOF-1 Chla (JJA: 98.2\%)

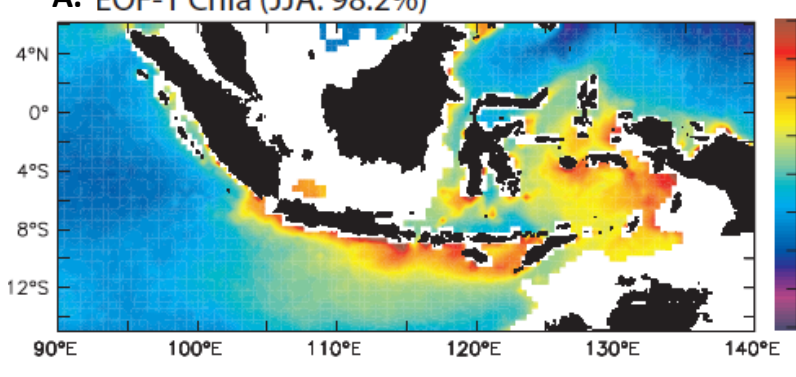

C. EOF-1 SST (JJA: 91.1\%)

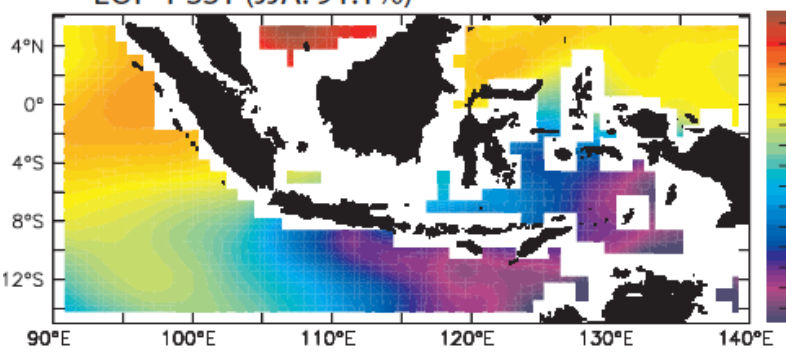

B. EOF-1 Ekman pumping (JJA: $86.8 \%)$

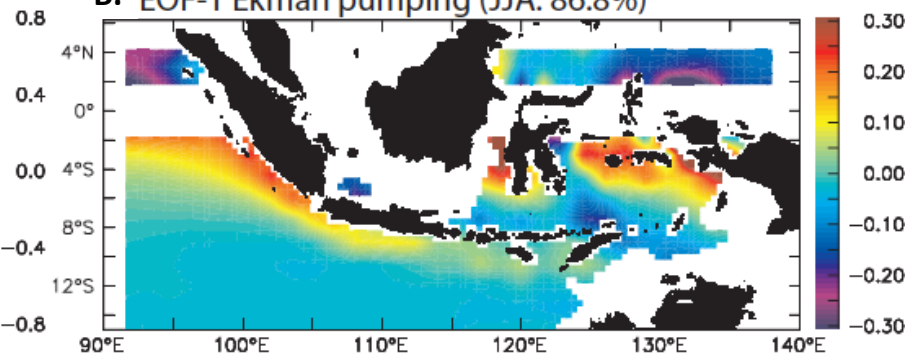

D. EOF-1 Wind-mixing (JJA: $85.9 \%)$

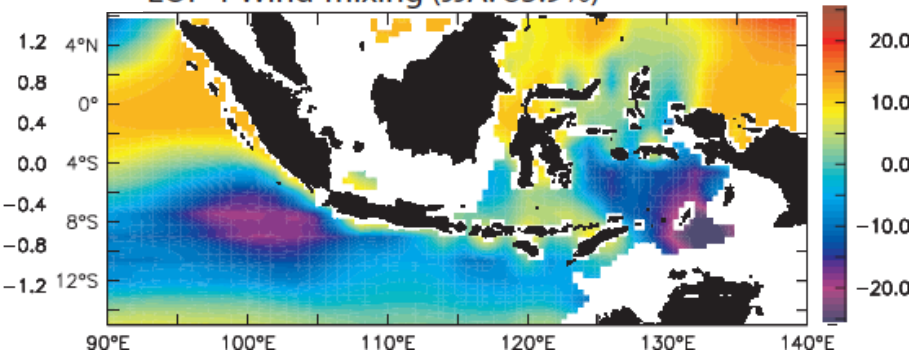

Figure 7. Same as in Figure 3 except for the first EOF mode for JJA season

The similarity between the first EOF spatial patterns of the full season and that of the JJA season was also found in the data analysis of the SST, Ekman pumping, and windinduced mixing (Figs. 7.B-D). The first EOF mode of the SST accounting for $91.1 \%$ of the total variance revealed negative weights that was $180^{\circ}$ out of phase with the chlorophyll- $a$ weights (Figure 7.B). In addition, the first EOF mode of the Ekman pumping, which explained 86.8\% of the total variance, showed positive weights in regions with positive weights of the chlorophyll- $a$ suggesting the presence of upwelling (Figure 7.C). Meanwhile, the first EOF spatial pattern of the wind-induced mixing accounts for $85.9 \%$ of the total variance. Its spatial pattern showed a prominent negative weight for wind-induced mixing in the west of Sumatra-Java and the east of Banda Sea (Figure 7.D) similar to that of the first EOF mode for the full season (Figure 3.D).

The time series of the principal component of the first EOF mode for the JJA season is presented in Figure 8.
Interestingly, only principal time series of SST and Ekman pumping showed significant correlation with the time series of DMI with coefficient correlation of -0.66 and 0.6 , respectively. Meanwhile, the principal time series of chlorophyll- $a$ and wind-induced mixing indicated the low correlation with the times series of DMI. The coefficient correlations for the chlorophyll- $a$ and wind-induced mixing were 0.34 and -0.42 , respectively. However, the principal time series of SST, Ekman pumping, and wind-induced mixing was significantly correlated to that of the chlorophyll- $a$, with coefficient correlation $>0.6$ (Table 4)

Table 3. Same as in Table 1 except for the first EOF mode of JJA and SON seasons.

\begin{tabular}{lcc}
\multicolumn{1}{r}{ Variables } & JJA & SON \\
\hline Chlorophyll & $98.2 \%$ & $98.1 \%$ \\
SST & $91.1 \%$ & $82.2 \%$ \\
Ekman pumping & $86.8 \%$ & $78.3 \%$ \\
Wind-induced mixing & $85.9 \%$ & $65.9 \%$ \\
\hline
\end{tabular}

A. PC EOF-1 Chla (JJA) and DMI ( $r=0.34)$

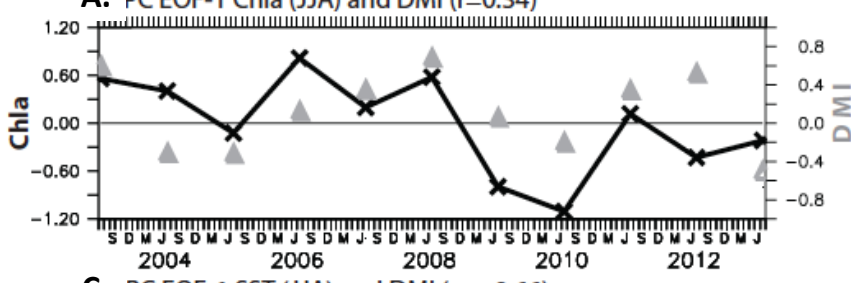

C. PC EOF-1 SST (JJA) and DMI $(r=-0.66)$

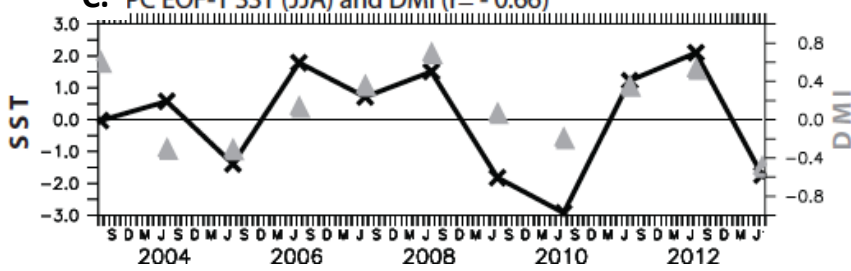

B. PCEOF-1 Ekman pumping (JJA) and DMI $(r=0.6)$

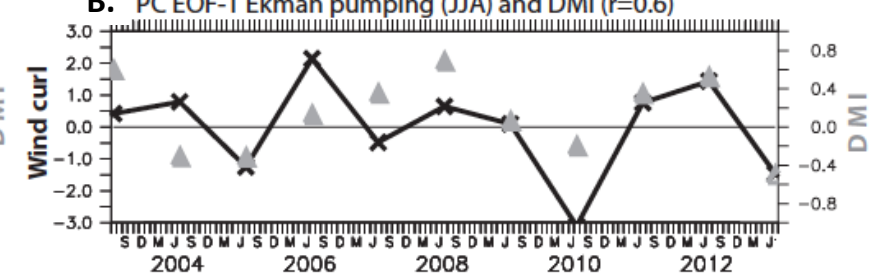

D. PCEOF-1 Wind-mixing (JJA) and DMI $(r=-0.42)$

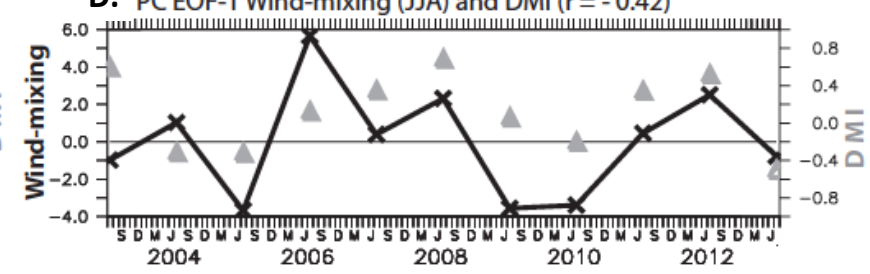

Figure 8. Same as in Figure 4 except for the first EOF mode for JJA season 
The spatial patterns of the first EOF mode of SON season are shown in Figure 9 and the explaination of variances are summarized in Table 3. Of the chlorophyll- $a$, the leading EOF mode accounts for $98.1 \%$ of the total variance and primarily revealed the changes of chlorophyll$a$ variation along the southern coast of Java and Nusa Tenggara Islands (Figure 9.A). Although the positive weights of the chlorophyll- $a$ variability was located in the negative weights of the SST, the greatest SST variability was further located in the west of Sumatra-Java as shown in the spatial pattern of the first EOF mode (Figure 9.B). Notably, the first EOF mode of the SST explained 82.2\% of the total variance and its spatial pattern resembled the second EOF mode pattern of the full season (Figure 5.B). The spatial pattern of the first EOF mode for the Ekman pumping, accounting for $78.3 \%$ of the total variance, showed the positive weights which were confined to the west coast of Sumatra and only the weak positive weights were found in south Java (Figure 9.C). The first EOF mode of the wind-induced mixing explained $65.9 \%$ of the total variance and its spatial pattern showed two distinct areas (Figure 9.D). The first area with strong negative windinduced mixing weights was found in the west of Sumatra-
Java, while the second area characterized by strong positive wind-induced mixing weights was located in the east of Timor Passage and so the temporal variability of these two regions was different from each other.

The principal component time series of the chlorophyll$a$ and SST was significantly correlated to the time series of DMI, with coefficient correlations of 0.62 and -0.94 , respectively (Figs. 10a-b). The principal component time series of the chlorophyll- $a$ and SST also demonstrated a significant correlation with a coefficient correlation of 0.75 (Table 4). On the other hand, the principal component time series of the Ekman pumping and wind-induced mixing did not show significant correlations with the time series of DMI (Figs. 10.C-D). In addition, the principal component time series of the Ekman pumping and windinduced mixing also did not show significant correlation with the chlorophyll- $a$ (Table 4). During the IOD year, weak surface winds were observed in all over the Indonesian regions. This result indicated that during the peak IOD season (SON season), the bloom of the chlorophyll- $a$ and the low SST in the SETIO region were generated by the strong upwelling favorable winds in the preceding season.

Table 4. Same as in Table 2 except for the JJA and SON seasons

\begin{tabular}{lcccc}
\hline & & IOD & \multicolumn{2}{c}{ Chlorophyll } \\
\cline { 2 - 5 } & JJA & SON & JJA & SON \\
\hline Chlorophyll & $0.34^{*}$ & $0.62^{*}$ & - & - \\
SST & $-0.66^{*}$ & $-0.94^{*}$ & $-0.69^{*}$ & $-0.75^{*}$ \\
Ekman Pumping & $0.60^{*}$ & 0.20 & $0.68^{*}$ & 0.20 \\
Wind-induced mixing & $-0.42^{*}$ & -0.10 & $-0.66^{*}$ & -0.03 \\
\hline
\end{tabular}

Note: $*$ Significant at $90 \%$ confidence level

A. EOF-1 Chla (SON: $98.1 \%)$

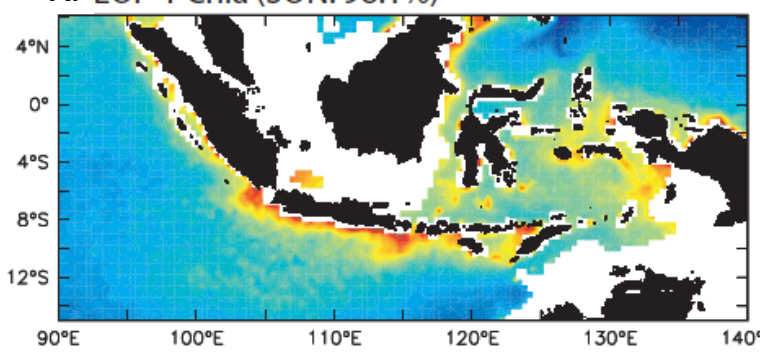

C. EOF-1 SST (SON: 82.2\%)

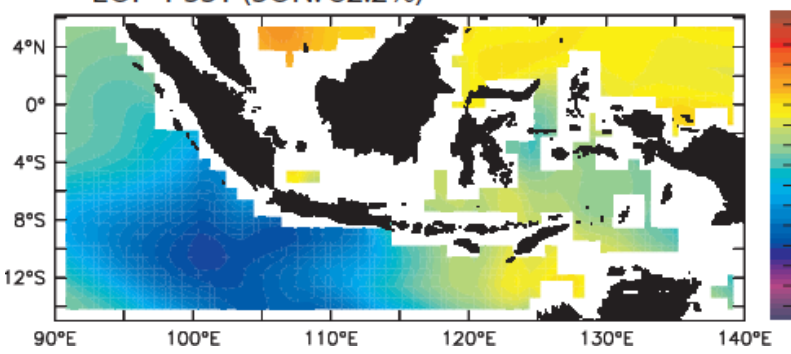

B. EOF-1 Ekman pumping (SON: 78.3\%)
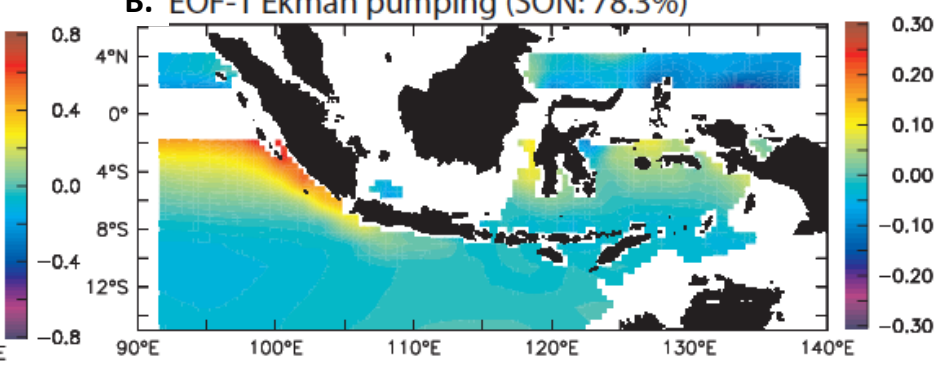

D. EOF-1 Wind-mixing (SON: 65.9\%)

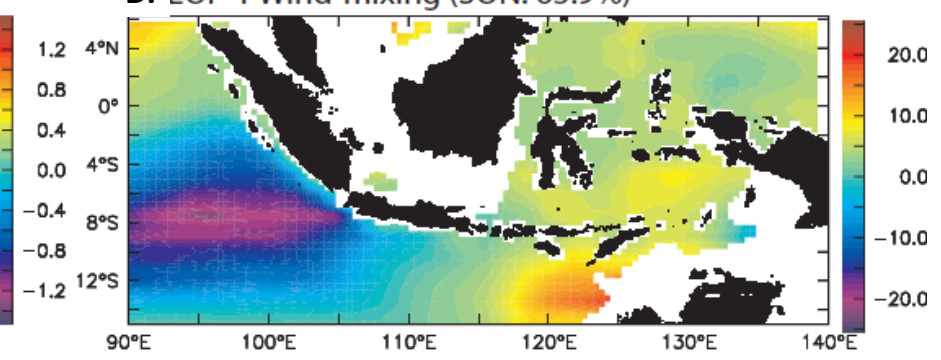

Figure 9. Same as in Figure 3 except for the first EOF mode for SON season 
A. PC EOF-1 Chla (SON) and DMl $(r=0.62)$

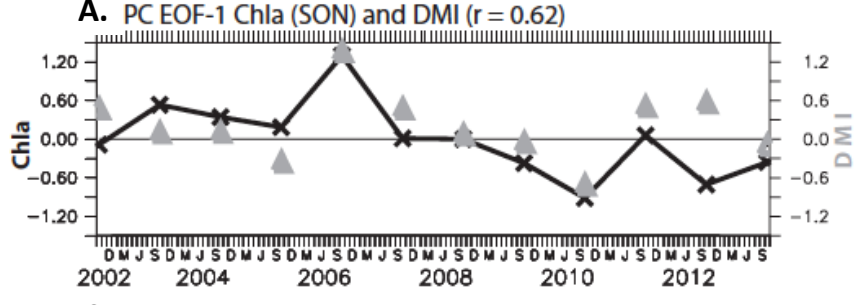

C. PCEOF-1 SST (SON) and DMl $(r=-0.94)$

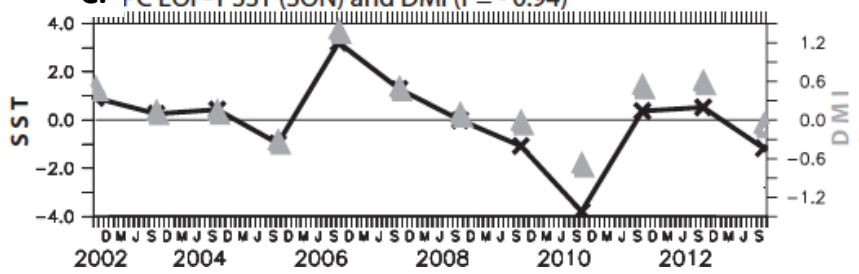

B. PC EOF-1 Ekman pumping (SON) and DMl $(r=0.2)$

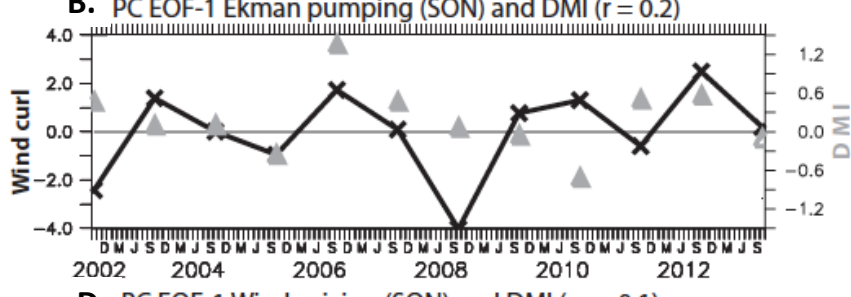

D. PC EOF-1 Wind-mixing (SON) and DMI $(r=-0.1)$

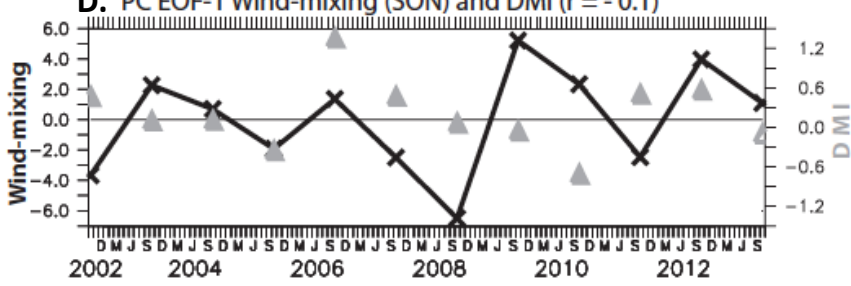

Figure 10. Same as in Figure 4 except for the first EOF mode for SON season

The SETIO region is strongly influenced by the Asianaustralian monsoon winds. Seasonal reversal of this monsoon winds causes seasonal coastal upwelling in the SETIO region, which occurs during the southeast monsoon. In some years, there was an anomalously strong coastal upwelling due to the enhancement of southeasterly winds along the southern coast of Sumatra and Java. This enhancement is associated with the occurrence of the IOD events in the tropical Indian Ocean.

In order to evaluate the interannual variation in the magnitude of seasonal chlorophyll- $a$ increase and its possible relationship with IOD events, we performed an EOF analysis on a multi-annual time series of seasonal average conditions for chlorophyll- $a$, SST, Ekman pumping, and wind-induced mixing. We choose the JJA and SON seasons because they represent the development and the peak phases of the IOD event, respectively. The results show that the chlorophyll- $a$ bloom during JJA season is mostly related to the seasonal upwelling generated by southeasterly winds during the southeast monsoon. Meanwhile, the EOF analysis on the SON season suggests that the anomalously strong upwelling-favorable winds during the development phase of the IOD event in JJA season provided a favorable condition for the chlorophyll- $a$ bloom during the peak phase of the IOD event in SON season. Although previous study has suggested that wind-induced mixing could bring subsurface nutrient-rich water to the mixed layer and lead to an increase in the chlorophyll- $a$ concentration (Ueyama and Monger 2005), our results suggest there is no correlation between chlorophyll- $a$ bloom and wind-induced mixing in the SETIO region.

\section{ACKNOWLEDGEMENTS}

Part of this study was conducted while the first author visited the Cornell University under the Fulbright Visiting
Senior Researcher program. The authors would like to thank the NASA Goddard Distributed Active Archive Center for the production and distribution of MODIS data. This study was supported by the Ministry of Research, Technology and Higher Education through "Penelitian Berbasis Kompetensi" (No: 454/UN9.3.1/LT/2017) and by the University of Sriwijaya through Hibah Profesi 2017 (No.1011/UN9.3.1/PP/2017). Part of this study was supported by a grant from the Asia-Pacific Network for Global Change Research (CAF2016-RR06-CMYSiswanto).

\section{REFERENCES}

Asanuma I, Matsumoto K, Okano H, Kawano T, Hendiarti N, Sachoemar SI. 2003. Spatial distribution of phytoplankton along the Sunda Islands: the monsoon anomaly in 1998. Journal of Geophyscal Research. 108. 3202. DOI: 10.1029/1999JC000139.

Carr M. E. 2002. Estimation of potential productivity in Eastern Boundary Currents using remote sensing. Deep-Sea Reseasrch. Part II. 49: 5980 .

Emery WJ, Thomson RE. 2004. Data Analysis Methods in Physical Oceanography. Elsevier, Amsterdam, Netherlands.

Feng M, Wijffels S. 2002. Intraseasonal variability in the South Equatorial Current of the East Indian Ocean. Journal of Physical Oceanogr aphy. 32. 265-277.

Horii T, Ueki I, Ando K, Mizuno K. 2013. Eastern Indian Ocean warming associated with the negative Indian Ocean dipole: A case study of the 2010 event. Jouranl of Geophysical Research Oceans. 118. 536-549. DOI: 10.1002 /jgrc.20071.

Iskandar I, Tozuka T, Sasaki H, Masumoto Y, Yamagata T. 2006. Intraseasonal variations of surface and subsurface currents off Java as simulated in a high-resolution ocean general circulation model. Jouranl of Geophysical Research Oceans. 111. C12015. DOI: 10.1029/2006JC003486.

Iskandar I, Rao SA, Tozuka T. 2009. Chlorophyll- $a$ bloom along the southern coasts of Java and Sumatra during 2006. International Journal of Remote Sensing. 30. 663-671.

Iskandar I, Sasaki H, Sasai Y, Masumoto Y, Mizuno K. 2010. A numerical investigation of eddy-induced chlorophyll bloom in the southeastern tropical Indian Ocean during Indian Ocean Dipole 2006. Ocean Dynamics. 60. 731-742. DOI: 10.1007/s10236-0100290-6. 
Iskandar I, Irfan M, Syamsuddin F. 2013. Why was the 2008 Indian Ocean Dipole a short-lived event? Ocean Science Journal. 48(2), 112.

McCreary JP, Murtugudde R, Vialard J, Vinayachandran PN, Wiggert JD, Hood RR, Shankar D, Shetye S.. 2013. Biophysical Processes in the Indian Ocean. In: Wiggert JD, Hood RR, Naqvi WA, Brink KH, Smith SL (eds) Indian Ocean Biogeochemical Processes and Ecological Variability. Geophysical Monograph Series. Vol. 185. pp. 9 - 32, AGU, Washington, D. C.

Murtugudde R, McCreary JP, Busalacchi AJ. 2000. Oceanic processes associated with anomalous events in the Indian Ocean with relevance to 1997-98. Journal of Geophysical Research. 105 (C2), 3295 - 3306.

Ogata T, Masumoto Y. 2010. Interactions between mesoscale eddy variability and Indian Ocean dipole events in the Southeastern tropical Indian Ocean: case studies for 1994 and 1997/1998. Ocean Dynamics. 60. 717-730. DOI: 10.1007/s10236-010-0304-4.

Pauly D, Christensen V. 1995. Primary production required to sustain global fisheries. Nature. 374, 255-257.

Quadfasel DR, Cresswell G. 1992. A note on the seasonal variability in the South Java Current. Jouranl of Geophysical Research Oceans. 97. 3685-3688.

Qu T, Meyers G. 2005. Seasonal characteristics of circulation in the southeastern tropical Indian Ocean. Journal of Physical Oceanography. 35 (2). 255-267.

Qu T, Du Y, Strachan J, Meyers G, Slingo J. 2005. Sea surface temperature and its variability in the Indonesian region. Oceanography. 18 (4). 50-61.

Reynolds RW, Rayner NA, Smith TM, Stokes DC, Wang WQ. 2002. An improved in situ and satellite SST analysis for climate. Journal of Climate. 15. 1609-1625.

Saji NH, Goswami BN, Vinayachandran PN, Yamagata T. 1999. A dipole mode in the tropical Indian Ocean. Nature. 410. 360 - 363.

Sprintall J, Chong J, Syamsudin F, Morawitz W, Hautala S, Bray NA Wijffels S. 1999. Dynamics of the South Java Current in the Indoaustralian basin. Geophysical Research Letters. 26. 2493 - 2496
Susanto RD, Marra J. 2005. Effect of the 1997/98 El Niño on chlorophyll$a$ variability along the southern coast of Java and Sumatra. Oceanography. 18. 124-127.

Susanto RD, Gordon AL, Zheng Q. 2001. Upwelling along the coasts of Java and Sumatra and its relation to ENSO. Geophysical Research Letters. 28 (8). 1599-1602.

Ueyama R, Monger B. 2005. Wind-induced modulation of seasonal phytoplankton blooms in the North Atlantic derived from satellite observations. Limnology and Oceanography. 50 (6). 1820-1829.

Webster PJ, Moore AW, Loschnigg JP, Leben RR. 1999. Coupled oceanatmosphere dynamics in the Indian Ocean during 1997-98. Nature. 401. 356 - 360 .

Weisberg RH, Wang C. 1997. Slow variability in the equatorial westcentral Pacific in relation to ENSO. Journal of Climate. 10. 1998 2017.

Wiggert JD, Vialard J, Behrenfeld MJ. 2013. Basin-Wide Modification of Dynamical and Biogeochemical Processes by the Positive Phase of the Indian Ocean Dipole During the SeaWiFS Era. In: Wiggert JD, Hood RR, Naqvi WA, Brink KH, Smith SL (eds) Indian Ocean Biogeochemical Processes and Ecological Variability. Geophysical Monograph Series. Vol. 185. pp. 9 - 32, AGU, Washington, D. C

Wijffels S, Meyers G. 2004. An intersection of oceanic waveguides: variability in the Indonesian throughflow region. Journal of Physical Oceanography. 34. 1232-1253.

Worley SJ, Woodruff SD, Reynolds RW, Lubker SJ, Lott N. 2005. ICOADS release 2.1 data and products. International Journal of Climatology. 25. 823-842. DOI: 10.1002/joc. 1166 .

Wyrtki K. 1961. Physical oceanography of the Southeast Asian waters: Scientific results of marine investigations of the South China Sea and the Gulf of Thailand 1959-1960. NAGA Report 2. Scripps Institute of Oceanography. La Jolla, CA.

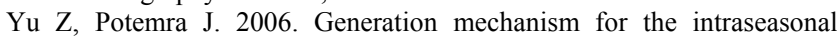
variability in the Indo-australian basin. Journal of Geophysical Research Oceans. 111. C02013. DOI: 10.1209/2005JC003023. 